\title{
Neonatal pre-auricular pits/sinuses: Survey of management strategies by pediatric otolaryngologists
}

\author{
Richard H. Schwartz ${ }^{1 \#}$, Vahe Badalyan ${ }^{2}$, Robert S. Bahadori ${ }^{2}$ \\ ${ }^{1}$ Departments of Pediatrics, Inova Fairfax Hospital for Children, Falls Church, USA \\ ${ }^{2}$ Departments of Surgery, Inova Fairfax Hospital for Children, Falls Church, USA \\ Email: ${ }^{\text {rhs738@aol.com }}$
}

Received 7 January 2012; revised 1 March 2012; accepted 21 March 2012

\section{ABSTRACT}

Background: Neonatal preauricular pit/sinus is a benign embryologic remnant of the first or second branchial arches. The estimated incidence in the US is 1 to 9/1000 newborns, higher in East Asian babies. Most remain asymptomatic throughout life. Inflammatory complications include discharge of squamous debris, cellulitis, or frank abscess. The purpose of this study was to survey pediatric otolaryngologists in the United States and Canada about management strategies for asymptomatic and symptomatic preauricular pits/sinuses. Study Design: A 15-item structured questionnaire covering questions on demographics, professional experience, and medical and surgical management of congenital preauricular pits/sinuses were sent by e-mail and selectively by regular mail to 273 members of the American Society of Pediatric Otolaryngology. Results: 175 of 273 responses (64\%) were evaluable. $85 \%$ of respondents would simply observe cases of asymptomatic preauricular pit/sinus. Regarding further evaluation, 122 respondents (70\%) would not recommend anything other than routine neonatal hearing screen, without need for repeat hearing tests in the first two years of life; 34 (19\%) would also get BAER hearing test and a renal ultrasound. If a sinus drains sebaceous material intermittently, 65\% of the surveyed pediatric otolaryngologists would recommend excision. Ninety nine percent of pediatric ENT respondents would excise a recurrently infected preauricular sinus. Conclusion: Watchful waiting, without requirement of periodic hearing tests in the first $\mathbf{2 4}$ months of life is certainly acceptable for management of neonatal asymptomatic preauricular pit/sinus. There is universal agreement that recurrently infected preauricular sinuses should be referred to a pediatric otolaryngologist for surgical excision of the fistulous tract.

\footnotetext{
*Financial Disclosures for all authors: No conflict of interest.

${ }^{\#}$ Corresponding author.
}

Keywords: Pre-Auricular Sinus; Pre-Auricular Pit

\section{INTRODUCTION}

Neonatal preauricular pit/sinus (also termed preauricular cyst) is a benign embryologic remnant of the first or second branchial arches. The low end of estimated incidence in the US is 1 per 1000 newborns, with boys and girls affected equally [1]. The incidence of preauricular pits/sinus is higher in China, Korea, and Japan.

A preauricular pit/sinus is usually located at or near the anterior margin of the ascending limb of the auricular helix. Preauricular pits/sinuses are usually unilateral. Bilateral preauricular pits/sinuses are more likely to be inherited, with an autosomal dominance with incomplete penetrance and variable expression. A preauricular pit is characterized by a closed dell or dimple or by an open sinus ostia. Preauricular sinus usually have an associated straight or branching sinus tract (not a true fistula), lined by squamous epithelium. The sinus tract can extend a median of $15 \mathrm{~mm}$ up to a maximum of several centimeters into the facial soft tissue. The sinus tracts almost always blend in with the perichondrium of the auricular cartilage.

Several syndromes, accounting for about 5\% of cases, are associated with preauricular pits. These include Branchio-Oto-Renal (BOR) syndrome (structural anomalies of the external, middle, and inner ear, hearing loss, and preauricular pits, lateral cervical fistulas, and renal anomalies-see discussion for more details), BeckwithWiedemann syndrome (Preauricular pit with asymmetric earlobes), Mandibulofacial dysostosis (Treacher-Collins Syndrome) and hemicranial microsomia syndrome (auricular pits/fistulas).

Most preauricular pits/sinuses remain asymptomatic throughout life [1-4]. Inflammatory complications include intermittent or continuous discharge of squamous debris from the orifice of a preauricular sinus tract, cellulitis, phlegmon, or frank abscess. Morbidity from preauricular pits/sinuses includes facial cellulitis, pyoderma, scarring, and ulceration of skin surrounding the sinus 
opening anterior to the auricle [1]. Preauricular sinus infections often recur after treatment with antibiotics. Recurrence after surgical removal ranges from $5 \%$ to $20 \%$, depending on the surgical technique and experience of the surgeon.

Management of preauricular pits/sinuses remains controversial for pediatricians and pediatric otolaryngologists. The main controversies are related to 1) performing renal sonography for neonates with an asymptomatic preauricular sinus to detect unsuspected renal anomalies; 2) obtaining follow-up hearing tests during the first three years of life; 3 ) timing of referral to an otolaryngologist; and 4) timing of definitive surgical correction. In a study that included 446 preauricular sinuses, only 15 (3.4\%) were associated with hearing loss or renal problems [1]. Some authors recommend renal sonogram only if the sinus is part of a syndrome or associated with other abnormalities [2].

Complete surgical extirpation of the pit, entire sinus tract(s), and a small piece of auricular cartilage provides the only definitive method to avoid recurrences. Opinion on timing of surgical correction ranges from extirpation of the sinus ostia and tract at the time of diagnosis, before infection occurs [2], to surgery after two or more infections.

The purpose of this study was to survey pediatric otolaryngologists in the United States and Canada about management strategies for preauricular pits/sinuses. We hoped, at the start of our survey that the Commonwealth of Virginia Early Hearing Detection and Intervention Program would revise then current policy of recommending repeat hearing screens twice annually until the age of three years for neonates born with any preauricular pits/ sinuses.

\section{METHODS AND ANALYSIS}

A 15-item structured questionnaire covering questions on demographics, professional experience, agreement with Virginia hearing screening policy, opinions regarding screening tests, referrals, medical and surgical management were sent to 273 members of the American Society of Pediatric Otolaryngology, for whom contact information was available. The survey was sent first by email. Non-respondents were sent a reminder email, and then mailed a hard copy of the questionnaire with $\$ 2$ bill enclosed, then another reminder email. In total, 3 series of emails and 1 hard copy mailing was sent to the prospective participants. Results were entered in Microsoft Excel (Microsoft, Redmond, WA) and analyzed in SPSS (SPSSInc., Chicago, IL). Frequencies of characteristics and responses were cross-tabulated.

\section{RESULTS}

Of 273 persons initially contacted by email and regular mail, 181 responded (66\%). Of those, 6 questionnaires were excluded because they contained blank responses to most questions, leaving 175 valid responses (64\%). Of the 175 respondents, 168 respondents (96\%) identified themselves as pediatric otolaryngologists (Table 1).

Nineteen respondents (11\%) agreed with the prior Virginia policy for screening infants with preauricular pit/sinus every 6 months till the age of 3 years (Table 2). Of the 6 respondents from Virginia, 1 person agreed and 5 disagreed with the prior policy.

For a newborn with an asymptomatic, non-syndromal preauricular pit/sinus, 122 respondents (70\%) would not recommend anything other than routine neonatal hearing screen Table 3). When asked about the timing of referral of an infant with preauricular pit/sinus to a specialist (not necessarily leading to immediate surgery), 44 respondents (25\%) suggested referring at the time of detecting the pit/sinus on physical examination (Table 4). A vast

Table 1. Practice setting of respondants.

\begin{tabular}{ccc}
\hline Practice setting & Number & Percent \\
\hline Private & 65 & 38.5 \\
University & 90 & 53.3 \\
Uncertain & 14 & 8.3 \\
Total & 169 & 100.0 \\
\hline
\end{tabular}

Table 2. Do Pediatric ENT MDs agree with serial hearing tests for Neonatal Preauricular pit/sinus.

\begin{tabular}{ccc}
\hline $\begin{array}{c}\text { Do you agree with previous Virginia } \\
\text { policy for additional hearing screening } \\
\text { after "passed” newborn hearing screen }\end{array}$ & Number & Percent \\
\hline Yes & 19 & 11.3 \\
No & 131 & 78.0 \\
Other & 18 & 10.7 \\
Total & 168 & 100.0 \\
\hline
\end{tabular}

Table 3. ENT responses to type of hearing test for newborn with preauricular pit/sinus.

\begin{tabular}{lcc}
\hline $\begin{array}{c}\text { How should a newborn with preauricularpit/ } \\
\text { sinus be evaluated for hearing deficit? }\end{array}$ & Number & Percent \\
\hline Newborn hearing screen & 122 & 72.2 \\
BAER & 10 & 5.9 \\
Newborn screen + BAER & 2 & 1.2 \\
Newborn screen + BAER + Renal US & 34 & 20.1 \\
No screen & 1 & 0.6 \\
Total & 169 & 100.0 \\
\hline
\end{tabular}


majority of respondents (85\%) would observe neonates with asymptomatic preauricular pit/sinus (Table 5). Only 9 respondents (5\%) recommended excision. Most respondents (65\%) would recommend excision in case of a non-infected preauricular sinus draining sebaceous material (Table 6).

Ninety-nine percent of respondentswould excise a preauricular sinus that became infected more than once (Table 7).

Table 4. Timing of referral of newborn with preauricular pit/ sinus to ENT.

\begin{tabular}{lcc}
\hline \multicolumn{1}{c}{ Timing of referral to specialist } & Number & Percent \\
\hline At the time of diagnosis & 44 & 25.3 \\
At time of first infection & 99 & 56.9 \\
For recurrent infections & 26 & 14.9 \\
Other (e.g. discharge, syndromes) & 5 & 2.9 \\
Total & 174 & 100.0 \\
\hline
\end{tabular}

Table 5. ENT opinion on management of never-infected preauricular pit/sinus.

\begin{tabular}{lcc}
\hline Management of never-infected sinus & Number & Percent \\
\hline Excision of entire tract & 9 & 5.1 \\
Observation & 149 & 85.1 \\
Other & 17 & 9.7 \\
Total & 175 & 100.0 \\
\hline
\end{tabular}

Table 6. ENT opinion on management of non-infected preauricular sinus draining sebaceous material.

\begin{tabular}{lcc}
\hline $\begin{array}{c}\text { Management of non-infected sinus } \\
\text { draining sebaceous material }\end{array}$ & Number & Percent \\
\hline Warm Packs & 53 & 31.2 \\
Incision and Drainage & 1 & 0.6 \\
Excision of entire tract & 114 & 67.1 \\
Other & 1 & 0.6 \\
Nothing & 1 & 0.6 \\
Total & 170 & 100.0 \\
\hline
\end{tabular}

Table 7. ENT management of recurrent infection of neonatal preauricular pit/sinus.

\begin{tabular}{lcc}
\hline $\begin{array}{c}\text { Management of recurrent infection } \\
\text { of pre-auricular sinus }\end{array}$ & Number & Percent \\
\hline Warm packs/antibiotics & 1 & 0.6 \\
Excision of entire tract & 173 & 99.4 \\
Total & 174 & 100.0 \\
\hline
\end{tabular}

\section{DISCUSSION}

Preauricular pits/sinuses are often a rather subtle finding on physical exam. There is a rare association between ear pits and some congenital syndromes like Branchio-OtoRenal Syndrome so neonatal audiologic screening of these infants is recommended. Major criteria for the diagnosis of Bronchio-Oto-Renal syndrome include second branchial arch anomalies, deafness, auricular deformity, renal anomalies, and preauricular pits [5]. Branchial cleft sinus tract appear as pinpoint openings anterior to the sternocleidomastoid muscle, usually in the lower third of the neck. An isolated branchial cleft cyst appears as a palpable mass under the SCM muscle, often above the level of the hyoid bone.

Management of asymptomatic and symptomatic (infected) preauricular sinus.

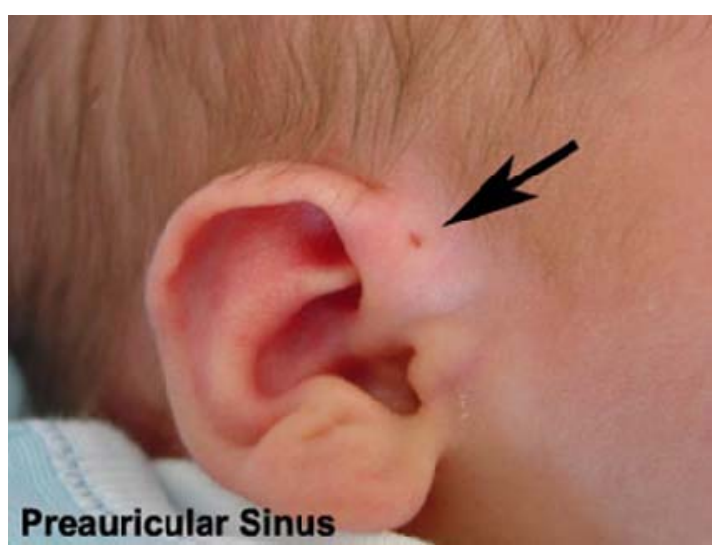

Source: http://embryology.med.unsw.edu.au/Notes/ear2.htm

No definitive studies have demonstrated that isolated preauricular pits/sinuses necessitate additional hearing assessment. The vast majority of the respondents to our survey of pediatric otolaryngologists (75\%) did not agree with Virginia's prior policy of repeat hearing tests every six months for the first 24 months of life for non-syndromic preauricular pit/sinus. Most survey respondents (85\%) would observe and do not recommend excision of an asymptomatic preauricular pit/sinus.

Management of infected preauricular sinuses with cellulitisincludesappropriate antibiotics for the first infection. Warm compress and antibiotics that are bactericidal for Staphylococcus aureus, the most common bacteria found in these infections are indicated in patients with cellulitis from infected preauricular sinuses.

Complete surgical excision of a preauricular sinus with tract or cyst is indicated in the setting of recurrent or persistent infection. The operation is typically performed when the acute infection has subsided. Recurrence rates of re-infection may be as high as $20 \%$. Factors that reduce the risk of recurrence include complete excision of the sinus and tract with associated perichondrium (auricu- 
lar cartilage as a posterior boundary), dissection down to temporalis fascia, while avoiding sinus tract rupture. Almost all respondents (99\%) would excise a preauricular sinus that became infected more than once.

Other than an instance where the patient has the rare Brachio-Oto-Renal Syndrome, usually accompanied by branchial cysts in the neck region, or other congenital/ syndromic anomalies, the presence of an asymptomatic neonatal preauricular pits/sinuses should be managed primarily by observation.

\section{REFERENCES}

[1] Tan, T., Constantinides, H. and Mitchell, T.E. (2005) The preauricular sinus: A review of its aetiology, clinical presentation and management. International Journal of
Pediatric Otorhinolaryngology, 69, 1469-1474. doi:10.1016/j.ijporl.2005.07.008

[2] Scheinfeld, N.S., Silverberg, N.B., Weinberg, J.M. and Nozad, V. (2004) The preauricular sinus: A review of its clinical presentation, treatment, and associations. Pediatric Dermatology, 21, 191-196. doi:10.1111/j.0736-8046.2004.21301.X

[3] Melnick, M. and Myrianthopoulos, N.C. (1979) External ear malformations: Epidemiology, genetics, and natural history. Alan R. Liss, New York.

[4] Prasad, S., Grundfast, K. and Milmoe, G. (1990) Management of congenital preauricular pit and sinus tract in children. Laryngoscope, 100, 320-321. doi:10.1288/00005537-199003000-00021

[5] Smith, R.J.H. (2012) Banchiootorenal spectrum disorders. Gene Reviews: NCBI Bookshelf. Http://www.ncbi.nlm.nih.gov/books/NBK1380/ 


\section{APPENDIX}

Questionnaire on Management of Congenital Preauricular Pit

1. The country/state in which you have your ENT practice

2. Specialty/subspecialty

a) General otolaryngology/HNS

b) Pediatric otolaryngology

3. Mark your practice setting, please.

a) Private practice

b) UniversityHospital

c) Other

4. In Virginia, the current recommendations for follow-up hearing tests for a newborn with preauricular sinus/ pit and normal newborn hearing screen include follow up twice yearly hearing tests - to age three years:

Do you agree with the need for audiological followup?
a) Yes
b) No
c) Uncertain

If Yes, why is this necessary?

5. Please mark your state's policy for repeat hearing tests when newborn has preauricular sinus/pit and passes the initial hearing screen.

a) No mandated repeat hearing screen

b) Hearing screen 1 more time

c) Screen 2 - 3 times

d) Screen $>3$ times after initial passed hearing screen

6. Number of years in specialty practice:
a) 1 - 2
b) 3 - 5
c) $6-10$
d) $>10$

7. Approximate number of children with preauricular sinus/pit in your career?
a) None
b) 1 - 2
d) 6- 10
e) 11 - 25
c) 3 - 5
f) $>25$

8. Evaluation of a newborn with preauricular sinus should include:

a) Newborn hearing screen b) BAER

c) a or b, and renal ultrasound

d) a or b, c, and echocardiogram

9. Does the evaluation differ if there were bilateral preauricular sinus/pits?
a) Yes
b) No
c) Uncertain

10. When should the primary care physician refer a child with congenital preauricularsinus(es) to a pediatric otolaryngologist?
a) At the time of diagnosis
b) At time of first infection
c) For recurrent infections
d) Other

11. My management of never-infected preauricular sinus includes:
a) Excision
b) No treatment
c) Other

12. My management of preauricular sinus draining sebaceous material, without inflammation includes:

a) Warm packs only

b) I \& D

c) Excision of entire sinus track

13. My management of primary infection of preauricular sinus includes:
a) Warm packs/antibiotics
b) Needle aspiration
c) I \& D (plus? antibiotics)
d) Excision of entire sinus track

14. My management of recurrent infection of preauricular sinus includes?

a) Warm packs and antibiotics

b) I \& D plus antibiotics, without excision

c) Excision, after a course of antibiotics

15. Do colleagues in your private practice or surgery section setting agree with your management plan for the questions 5 - 11?
a) Yes
b) No
c) Uncertain 